\title{
OS RESÍDUOS SÓLIDOS E SEUS EFEITOS NEGATIVOS
}

Leidyanne Alves de Lima ${ }^{1}$

\begin{abstract}
RESUMO. De acordo com dados da Abrelpe( Associação Brasileira das Empresas de Limpeza Pública e Resíduos Especiais) no ano de 2016, cerca de 41,6\% de todo resíduo produzido no Brasil teve destino inadequado, sendo depositado em lixões e aterros controlados. Mesmo depois de implantada a PNRS( Política Nacional de Resíduos Sólidos) em 2010, o problema da destinação inadequada dos resíduos ainda persiste no Brasil, mostrando que é necessário existir mais interesse por parte do conjunto (empresa, sociedade e poder público) para ter um meio ambiente equilibrado. Em vista disso, o presente trabalho foi elaborado para mostrar e discutir os impactos ambientais ocasionados pela pela falta de adequação no destino dos resíduos sólidos, trazendo conceituações e dados sobre o tema. Esta pesquisa foi feita através de estudos de diversos artigos encontrados nas bases de dados Scielo e Capes, porém também foram utilizados outros documentos encontrados em sítios de busca da internet.
\end{abstract}

Palavras chave: Resíduos sólidos; lixo; adequação.

\section{SOLID WASTE AND ITS NEGATIVE EFFECTS}

\begin{abstract}
According to data from Abrelpe (Brazilian Association of Public Cleaning and Special Waste Companies) in 2016, approximately $41.6 \%$ of all waste produced in Brazil had an inadequate destination and was deposited in landfills and landfills. Even after the PNRS (National Solid Waste Policy) was implemented in 2010, the problem of inadequate waste disposal still persists in Brazil, showing that it is necessary to have more interest on the part of the whole (company, society and public authority) to have a environment. In view of this, the present work was elaborated to show and to discuss the environmental impacts caused by the lack of adequacy in the destination of the solid residues, bringing conceptualizations and data on the subject. This research was done through studies of several articles found in the databases Scielo and Capes, but also used other documents found in internet search sites.
\end{abstract}

Keywords: solid waste; trash; adequacy..

\section{LOS RESIDUOS SÓLIDOS Y SUS EFECTOS NEGATIVOS}

Resumen. De acuerdo con datos de Abrelpe (Asociación Brasileña de las Empresas de Limpieza Pública y Residuos Especiales) en el año 2016, cerca del 41,6\% de todo residuo producido en Brasil tuvo destino inadecuado, siendo depositado en basurales y vertederos controlados. En el año 2010, el problema de la destinación inadecuada de los residuos aún persiste en Brasil, mostrando que es necesario que exista más interés por

\footnotetext{
${ }^{1}$ Universidade Federal de Campina Grande - UFCG
} 
parte del conjunto (empresa, sociedad y poder público) para tener un producto medio ambiente equilibrado. En vista de ello, el presente trabajo fue elaborado para mostrar y discutir los impactos ambientales ocasionados por la falta de adecuación en el destino de los residuos sólidos, trayendo conceptualizaciones y datos sobre el tema. Esta investigación fue hecha a través de estudios de diversos artículos encontrados en las bases de datos Scielo y Capes, pero también se utilizaron otros documentos encontrados en sitios de búsqueda de internet.

Palabras clave: residuos sólidos; residuos; adecuación

\section{Introdução}

O volume de resíduos produzidos mundialmente aumentou vertiginosamente depois da Revolução Industrial, tal acontecimento histórico foi marcado pela utilização de máquinas para a produção e não mais pela única e exclusiva mão de obra humana o que tornou a fabricação um procedimento mais simples.

Os modos de produção avançaram e a partir daí a facilidade para se adquirir produtos fez com que muitas pessoas começassem a consumir desenfreadamente, e atualmente as pessoas consomem não mais para atenderem às suas necessidades pessoais, mas para se adequarem aos padrões da sociedade, causando deste modo, sérios prejuízos ambientais pelo volume de lixo gerado.

Tendo em vista essa problemática o presente trabalho foi elaborado para mostrar e discutir os impactos ambientais ocasionados pela falta de adequação no destino dos resíduos sólidos trazendo conceituações e dados sobre o tema.

\section{Metodologia}

Realizou-se uma pesquisa através de estudos de diversos artigos encontrados nas bases de dados Scielo e Capes, porém também foram utilizados outros documentos encontrados em sítios de busca da internet.

Esse é um trabalho de revisão bibliográfica pois segundo Alves, uma pesquisa é considerada de revisão quando ela é desenvolvida a partir de fontes já elaboradas, livros, artigos científicos, publicações periódicas, as chamadas fontes de papel. Semelhantemente, Severino conceitua essa modalidade como de pesquisas feitas a partir de registros e decorrentes de ideias já existentes. 


\section{Resultados e discussões}

Os resíduos sólidos são muitas vezes denominados de lixo, porém para vários autores existem algumas diferenças entre esses dois termos sendo o primeiro definido como algo que pode ser reaproveitado e reciclado e o segundo como aquilo que não tem mais nenhuma utilidade para o ser humano.

Segundo SILVA resíduos são materiais resultantes do processo de produção, transformação, utilização ou consumo, oriundos de atividades humanas ou animais, ou decorrentes de fenômenos naturais, a cujo descarte se procede, se propõe proceder ou se está obrigado a proceder. (SILVA, 2003, p.48).

Já para a Associação Brasileira de Normas Técnicas resíduo é algo em estado sólido e semissólidos, produtos da ação da indústria, de atividades domésticas, do comércio, de serviços agrícolas e também de serviços hospitalares (ABNT, 2004).

De acordo com dados da Abrelpe (Associação Brasileira das Empresas de Limpeza Pública e Resíduos Especiais) no ano de 2016, cerca de 41,6\% de todo resíduo produzido no Brasil teve destino inadequado, sendo depositados em lixões e aterros controlados.

Os famosos lixões são locais onde o lixo fica depositado a céu aberto para ser decomposto pela ação tempo, já os aterros controlados diferem dos lixões pelo fato do lixo ser recoberto por uma camada de terra, porém esta última ainda é inadequada porque o lixo produz chorume, que contamina o solo e pode também chegar a contaminar as águas.

Os lixões causam vários problemas como, odores degradáveis, poluição visual, contaminação de águas subterrâneas e superficiais, proliferação de insetos e roedores e como consequência deste último, o aumento de doenças. (Mota, 1981)

Melhores alternativas são a incineração e o aterro sanitário, porém até estes se não forem feitos de maneira adequada podem causar prejuízos ambientais e ao homem. A incineração é adequada para o destino dos lixos hospitalares pois dessa forma elimina-se qualquer tipo de agente patogênico, mas se não tiver filtros causa a poluição do ar. Do mesmo modo os aterros sanitários são meios apropriados, no entanto, se não tiver uma boa infraestrutura e não for feita a drenagem do líquido percolado (chorume) pode ocasionar poluição. 
A contaminação das águas por resíduos é algo preocupante, principalmente em regiões do nordeste, pois em períodos de seca em diversas cidades uma das únicas alternativas que se tem para se obter água é através de poços subterrâneos. Muitas pessoas cavam poços rasos em diversas localidades sem ao menos saber se ela é própria para consumo correndo-se, o risco de ela estar contaminada por chorume, Necrochorume( chorume de cemitérios) e até mesmo metais pesados.

Outro grande problema diz respeito ao chamado lixo eletrônico, estima-se que em 2016 cerca de 1,5 milhão de toneladas desse tipo de lixo foi gerado no Brasil. E a culpa por esse grande volume de lixo eletrônico gerado na atualidade, é atribuída a obsolescência rápida dos eletrônicos.

O problema dos resíduos perdura, sendo que para Lemos, os danos ambientais além de decorrerem de múltiplas causas podem se manifestar depois de um transcurso de tempo e também alcançar regiões transfronteiriças.

No Brasil já existem algumas leis como a PNRS( Política Nacional dos Resíduos Sólidos) que estabelece princípios, objetivos, metas e diretrizes com prazos definidos, para otimizar o gerenciamento dos resíduos.

A PNRS visa participação integrada de empresas, sociedade e poderes públicos para conseguir realizar seus objetivos pois não é possível atingir as metas quando qualquer um destes agentes não participa.

Dentre os vários princípios da PNRS tem-se a logística reversa que é o retorno do produto descartado para quem o produziu, pois o fabricante sabe qual melhor destino daquele resíduo, se ainda é possível reciclar ou reutilizá-lo. Sendo que essa estratégia se torna muito benéfica principalmente para o lixo eletrônico.

A PNRS define logística reversa como:

[...] instrumento de desenvolvimento econômico e social caracterizado por um conjunto de ações, procedimentos e meios destinados a viabilizar a coleta e a restituição dos resíduos sólidos ao setor empresarial, para reaproveitamento, em seu ciclo ou em outros ciclos produtivos, ou outra destinação final ambientalmente adequada. (Lei 12.305/10, Inciso XII)

Leite conceitua logística reversa como sendo a área da logística empresarial que planeja opera e controla o fluxo e as informações logísticas com retorno dos bens de pós venda e consumo. 
Já Lacerda define como um processo complementar a logística tradicional onde trás de volta os produtos já utilizados passando por um processo de reciclagem e voltam novamente à cadeia, até ser finalmente descartado.

\section{Conclusão}

O crescente aumento de resíduos produzidos pela população brasileira gera grandes impactos ambientais e torna-se até mesmo um problema de saúde pública, sendo premente a necessidade de existir mais interesse por parte do conjunto (empresa, sociedade e poder público) com vista a se ter um meio ambiente equilibrado.

É de suma importância existirem políticas públicas no sentido de educar a população a reduzir os consumos, reutilizar, reciclar e incentivar a optar por produtos que sejam ambientalmente sustentáveis sendo preciso também que as penalidades com relação ao não cumprimento das exigências da PNRS sejam mais rigorosas.

\section{Referências}

ALVES, M. Como escrever teses e monografia: um roteiro passo a passo. Rio de Janeiro: Elsevier, 2007.

ASSOCIAÇÃO BRASILEIRA DE NORMAS TÉCNICAS - ABNT. NBR 10.004: Classificação de resíduos sólidos: Rio de Janeiro, 2004.

BRASIL. Lei $\mathrm{n}^{\circ}$ 12.305, de 2 de agosto de 2010. Institui a Política Nacional de Resíduos Sólidos; altera a Lei no 9.605, de 12 de fevereiro de 1998; e dá outras providências. Disponível em: <http://www.planalto.gov.br/ccivil_03/_ato20072010/2010/lei/112305.htm> acesso em 10/03/2018.

Mesmo com política de resíduos, $41,6 \%$ do lixo tem destino inadequado, disponível em <http://g1.globo.com/natureza/noticia/2015/07/mesmo-com-politica-de-residuos416-do-lixo-tem-destino-inadequado.html > acesso em 10/03/2018

MOTA, Seutônio. Planejamento urbano e preservação ambiental. Fortaleza: Edições UFC, 1981.p. $209-237$

LACERDA, Leonardo. Logística reversa: uma visão sobre os conceitos básicos e operacionais.Mai.Disponívelem: $<$ http://www.sargas.com.br/site/index.phpoption=com_ content\&task=view\&id=78\&Itemid=29> . Acesso em: 15 jan. 2012.

LEITE, Paulo Roberto. Logistica Reversa: Meio Ambiente e Competitividade. São Paulo: Pearson Prentice Hall, 2005. 
LEMOS, Patrícia Faga Iglesias. Resíduos Sólidos e Responsabilidade Civil Pós Consumo.São Paulo: Revista dos Tribunais, 2011.

SEVERINO, A. J. Metodologia do trabalho científico. São Paulo: Cortez, 2007.

SILVA, C. E.; HOPPE, A. E. Diagnóstico dos Resíduos de Serviço de Saúde no interior do Rio Grande do Sul. Revista Engenharia Sanitária e Ambiental, v. 10, n. 2, p.146$151,2005$. 